\title{
Avaliação do processo de fluoretação nos sistemas de abastecimento de água da região de Araçatuba, São Paulo
}

\author{
Evaluation of the fluoridation in the water supply \\ systems of Araçatuba, São Paulo, Brazil
}

\begin{abstract}
Flávio Daré
Engenheiro Civil pela Escola de Engenharia de São Carlos da Universidade de São Paulo (EESC/USP). Mestre em Engenharia Civil, Recursos Hídricos e Tecnologias Ambientais pela Faculdade de Engenharia de Ilha Solteira da Universidade Federal de São Paulo (FEIS/UNESP)
\end{abstract}

\section{Milton Dall'Aglio Sobrinho}

Engenheiro Civil, Mestre e Doutor em Hidráulica e Saneamento pela EESC/USP. Professor-associado do Departamento de Engenharia Civil da FEIS/UNESP

\section{Marcelo Libânio}

Engenheiro Civil e Mestre em Engenharia Sanitária pela Universidade Federal de Minas Gerais (UFMG). Doutor em Hidráulica e Saneamento pela EESC/USP. Professor-associado do Departamento de Engenharia Hidráulica e Recursos Hídricos da UFMG

\begin{abstract}
Resumo
O trabalho visa avaliar a efetividade da fluoretação da água de consumo nos sistemas da microrregião de Araçatuba (SP) por meio de 5.157 análises de flúor realizadas no período de 2001 a 2005. Os dados foram analisados com relação ao tipo de manancial e à estrutura dos sistemas, representada pela população dos municípios e tipo de administração. Verificou-se que $51,6 \%$ das amostras não atenderam ao padrão de fluoretação e que o maior percentual de atendimento ocorreu nos sistemas operados pela Sabesp (69\%), seguidos pelos Grandes (52,1\%), estatisticamente semelhantes aos Médios (51,4\%), e pelos Pequenos (28\%). Sistemas que utilizam água superficial apresentaram desempenho estatisticamente superior ao padrão (60\%) em relação aos que utilizam água subterrânea (42,9\%). Dentre os últimos, os que exploram o aquífero Guarani foram superiores (52,3\%) aos outros $(46,6 \%)$.
\end{abstract}

Palavras-chave: fluoretação; controle da qualidade da água; padrão de flúor; vigilância de qualidade de água.

\begin{abstract}
This paper focuses on the drinking-water fluoridation process in Araçatuba region water supply systems by means of 5.157 fluoride concentration data from 2001 to 2005. These data were studied based on the water source, the administration and the structure of the water supply system, according to the population of the county and the type of management. Almost half of samples did not comply the fluoridation standard and the higher compliance was verified in the water supply systems operated by Sabesp (69\%), followed by the group of Large counties (52\%), statistically similar to the Medium ones $(51.4 \%)$, and better than the Small ones (28\%). The systems with surface intakes showed statistically higher performance in the compliance to the standard (60\%) compared to the ones that use groundwater (42.9\%). In this last group, those that explore the Guarani aquifer were superior (52.3\%) than the others $(46.6 \%)$.
\end{abstract}

Keywords: fluoridation; drinking-water quality; optimum fluoride level; drinking-water surveillance. 


\section{Introdução}

Em relação ao foco deste trabalho, pode-se afirmar que a fluoretação ou fluoração consiste na etapa do tratamento na qual se objetiva conferir, para a significativa maioria das águas naturais, determinada concentração de fluoreto (F-) na água tratada por meio da aplicação de compostos de flúor. Esse processo visa à prevenção da cárie dentária, principalmente em crianças até 12 anos, minimizando o risco da fluorose.

Os benefícios da fluoretação das águas de consumo têm sido confirmados por diversos estudos a partir da década de 1920. Em meados da década de 1940, quando teve início o processo de fluoretação nos Estados Unidos, avaliações do percentual de cáries em crianças de 12 a 14 anos em quatro cidades americanas e uma canadense apontaram redução de 50 a 65\% de incidência. Em 1992, realizava-se fluoretação em aproximadamente 10.500 sistemas de abastecimento americanos - incluindo cidades, distritos e povoados -, atendendo a mais de 135 milhões de pessoas, englobando mais de 70\% das cidades com população superior a 100 mil habitantes (42 das 50 maiores cidades americanas). No Canadá essa estimativa atingia mais de 50\% da população (REEVES, 1999).

Estabelecida pelo Serviço Norte-Americano de Saúde Pública (USPHS, United States Public Health Service) em meados da década de 1950, a concentração recomendada de flúor nas águas de abastecimento baliza-se pela média das temperaturas máximas diárias do ar em um período mínimo de cinco anos. Dessa forma, a concentração recomendada pode ser determinada por meio da Equação 1.

$C=22,2 /(10,3+0,725 \mathrm{~T})$

Equação 1

onde:

C: concentração de flúor (mg.L-1);

T: média das temperaturas máximas diárias em um período mínimo de um ano $\left({ }^{\circ} \mathrm{C}\right)$.

Como consequência do início da fluoretação das águas de consumo nos Estados Unidos, logo após a 2 a Grande Guerra, a concentração máxima de flúor recomendada foi inserida no padrão de potabilidade americano de 1962, variando de 0,8 a 1,7 mg. $\mathrm{L}^{-1} \mathrm{em}$ função do clima da região.
No Brasil, a primeira aplicação do flúor em estações de tratamento de água teve início em 1953 no Espírito Santo (Baixo Guandu) pela Fundação Serviços Especiais de Saúde Pública (Fundação SESP, atual Fundação Nacional de Saúde, Funasa) e sua regulamentação em nível nacional ocorreu em 1974. De acordo com o Ministério da Saúde, estima-se que, em 1997, 65,5 milhões de brasileiros (42\% da população) tinham acesso à água fluoretada.

A Portaria 635/Bsb (BRASIL, 1977), em seu inciso IV, estabelece que a concentração recomendada de íon fluoreto (mg. $\mathrm{L}^{-1}$ ) nas águas de abastecimento público é obtida por uma equação idêntica à pela Equação 1 do USPHS. O anexo da Portaria 635/Bsb estabelece os limites recomendados para a concentração do íon fluoreto em função da média das temperaturas máximas diárias, reproduzidos na Tabela 1 .

A Portaria 518 do Ministério da Saúde (BRASIL, 2004) estabelece apenas concentração máxima de flúor de $1,5 \mathrm{mg} \cdot \mathrm{L}^{-1}$ e as concentrações empregadas pela maioria das concessionárias são praticamente coincidentes às da USPHS. A Portaria 518 substituiu a Portaria 1469, publicada em dezembro de 2000, mantendo praticamente inalterados o número e os valores máximos permissíveis de cada parâmetro

Uma das mais importantes premissas estabelecidas pela Portaria 518 (BRASIL, 2004) refere-se ao controle e à vigilância da qualidade de água. O primeiro é realizado pela concessionária responsável pela operação do serviço de abastecimento de água. A realização da vigilância cabe ao Ministério da Saúde, por meio das secretarias estaduais, no sentido de verificar se a água distribuída atende às premissas estabelecidas pelo padrão de potabilidade, além de avaliar os riscos à saúde da população abastecida.

No Estado de São Paulo, antecipando-se à própria Portaria 1469 (publicada em 2000 e sucedida pela Portaria 518), a Secretaria de Estado da Saúde, por intermédio do Centro de Vigilância Sanitária (CVS), implantou em 1988 o programa estadual de vigilância da qualidade da água para consumo humano denominado Proágua e oficializado em janeiro de 1992 pela Resolução 45. Esse programa tem como objetivo principal a redução de doenças de veiculação hídrica mediante vigilância da qualidade da água consumida pela população, principalmente em sistemas públicos, porém não neglicenciando os sistemas alternativos coletivos ou os alternativos individuais de abastecimento.

Tabela 1 - Limites recomendados para a concentração do íon fluoreto em função da média das temperaturas máximas diárias

\begin{tabular}{|c|c|c|c|}
\hline \multirow{2}{*}{$\begin{array}{l}\text { Média das temperaturas máximas } \\
\text { diárias }\left({ }^{\circ} \mathrm{C}\right)\end{array}$} & \multicolumn{3}{|c|}{$\begin{array}{l}\text { Limites recomendados para a } \\
\text { concentração do íon fluoreto }\left(\mathrm{mg} \cdot \mathrm{L}^{-1}\right)\end{array}$} \\
\hline & Mínimo & Máximo & Ótimo \\
\hline $10,0-12,1$ & 0,9 & 1,7 & 1,2 \\
\hline $12,2-14,6$ & 0,8 & 1,5 & 1,1 \\
\hline $14,7-17,7$ & 0,8 & 1,3 & 1,0 \\
\hline $17,8-21,4$ & 0,7 & 1,2 & 0,9 \\
\hline $21,5-26,3$ & 0,7 & 1,0 & 0,8 \\
\hline $26,4-32,5$ & 0,6 & 0,8 & 0,7 \\
\hline
\end{tabular}


A estratégia do Programa consiste na avaliação do potencial de risco dos sistemas de abastecimento de água. Para tanto, os técni$\cos$ das equipes da Vigilância Sanitária realizam sistematicamente visitas de inspeção sanitária aos sistemas para verificar condições de operação e manutenção. Além das inspeções sanitárias, efetua-se a coleta de amostras para análise em laboratório de Saúde Pública, verificando-se a potabilidade mediante determinação de parâmetros físico-químicos e bacteriológicos, como o teor de flúor, em termos de concentração de fluoreto.

Apesar dos aspectos positivos da fluoretação de águas de abastecimento, dados recentes de bibliografia apontam para a existência de dificuldades na obediência aos padrões de fluoretação nos sistemas brasileiros, algumas ainda não foram suficientemente analisadas, além de evidenciar importância do controle externo dessa operação. Por exemplo, Lima et al (2004), a partir de amostras de 16 pontos da rede de distribuição de Pelotas (RS) ao longo de 24 meses, identificaram significativa variação em cada ponto ao longo do período e aproximadamente 50\% dos pontos amostrados apresentaram níveis não ótimos de flúor. Concluiu-se que o controle se mostrou essencial uma vez que os níveis de flúor na água variaram demasiadamente ao longo do período de monitoramento. Situação semelhante é relatada por Maia et al (2003), com dados do controle da fluoretação em Niterói (RJ) entre janeiro e dezembro de 2000. Os autores encontraram 96\% das amostras inadequadas e incoerências entre as medições pelos responsáveis na estação de tratamento e os resultados das análises independentes das amostras de água. Situação distinta foi relatada por Ramires et al (2006), em monitoramento de um ano na cidade de Bauru (SP), onde foram encontradas $84,7 \%$ das amostras atendendo ao padrão.

Paralelamente a essas constatações, observa-se que as premissas estabelecidas pela USPHS têm sido questionadas pela mudança de costumes e pela própria evolução tecnológica verificada nos últimos 50 anos. Por um lado, o uso corrente de dentifrícios à base de flúor e a variedade de bebidas passíveis de substituírem a água de consumo, e por outro - ainda que para a parcela mais abastada da população o emprego extensivo de ar condicionado nos diversos ambientes, tendem a reduzir o consumo de água nos períodos mais quentes do dia (LALUMANDIER; JONES, 1999).

\section{Objetivo}

Em vista do exposto, propõe-se avaliar a eficiência do processo de fluoretação da água de 40 municípios da região de Araçatuba (SP), balizada no atendimento à Portaria 518 (BRASIL, 2004), por meio de 5.157 análises de flúor realizadas no período de 2001 a 2005. Pretende-se, em primeira instância, caracterizar o quadro de atendimento dos sistemas à legislação sobre fluoretação e, em seguida, identificar possíveis características dos sistemas responsáveis pela explicação dos resultados encontrados. Para tanto, foram analisadas as performances de grupos de sistemas no que tange à magnitude da população abastecida, ao tipo de captação e ao tipo de operação do sistema de abastecimento (prefeitura municipal e companhia estadual de saneamento).

\section{Metodologia}

\section{Descrição do universo amostral}

O universo amostral da pesquisa abarcou os sistemas de abastecimento de água de 40 municípios da microrregião de Araçatuba fiscalizados pela Vigilância Sanitária, com população total estimada, em 2005, de 693 mil habitantes. Dessa amostra, 15 sistemas são operados pela Companhia de Saneamento Básico do Estado de São Paulo (Sabesp) e os demais, pelas próprias prefeituras municipais. Devido ao gerenciamento operacional mais uniforme característico de algumas companhias estaduais de saneamento, os municípios operados pela Sabesp foram reunidos num único agrupamento.

Dos 25 municípios restantes, quatro foram classificados como grandes por contarem com população superior a 50 mil habitantes (Andradina, Araçatuba, Birigui e Penápolis) e representarem significativo percentual das análises. Dos 21 municípios restantes, sete foram classificados como médios: Buritama, Castilho, Guararapes, Ilha Solteira, Mirandópolis, Pereira Barreto, e Valparaíso. Apresentam população entre 10 mil e 50 mil habitantes, características de operação semelhantes entre si e dificuldades relacionadas principalmente à carência de mão-de-obra especializada. Os 14 municípios restantes contam com menos de 10 mil habitantes, cujos sistemas de abastecimento são operados pela própria Prefeitura Municipal, alguns inclusive sem realizar a fluoretação. Na Figura 1 apresentam-se os municípios integrantes do universo amostral da pesquisa.

Outro corte de análise referiu-se ao tipo de manancial explorado: superficial, aquífero artesiano e aquífero freático, de acordo com a seguinte nomenclatura:

- $\quad$ superficial: captação em cursos d'água represados ou não;

- subterrânea (aquífero freático): captação em poço tubular profundo que explora o aquífero Bauru ou Serra Geral (máximo de $200 \mathrm{~m}$ de profundidade);

- $\quad$ profundo (aquífero artesiano): captação em poço tubular profundo que explora os aquíferos Botucatu e Piramboia, também denominados Guarani (poços que excedem 1.000 m de profundidade na região em estudo).

Visando estudar de forma mais ampla os aspectos envolvidos no desempenho da fluoretação, efetuou-se também uma análise distinta com base na correlação com o Índice de Desenvolvimento Humano 


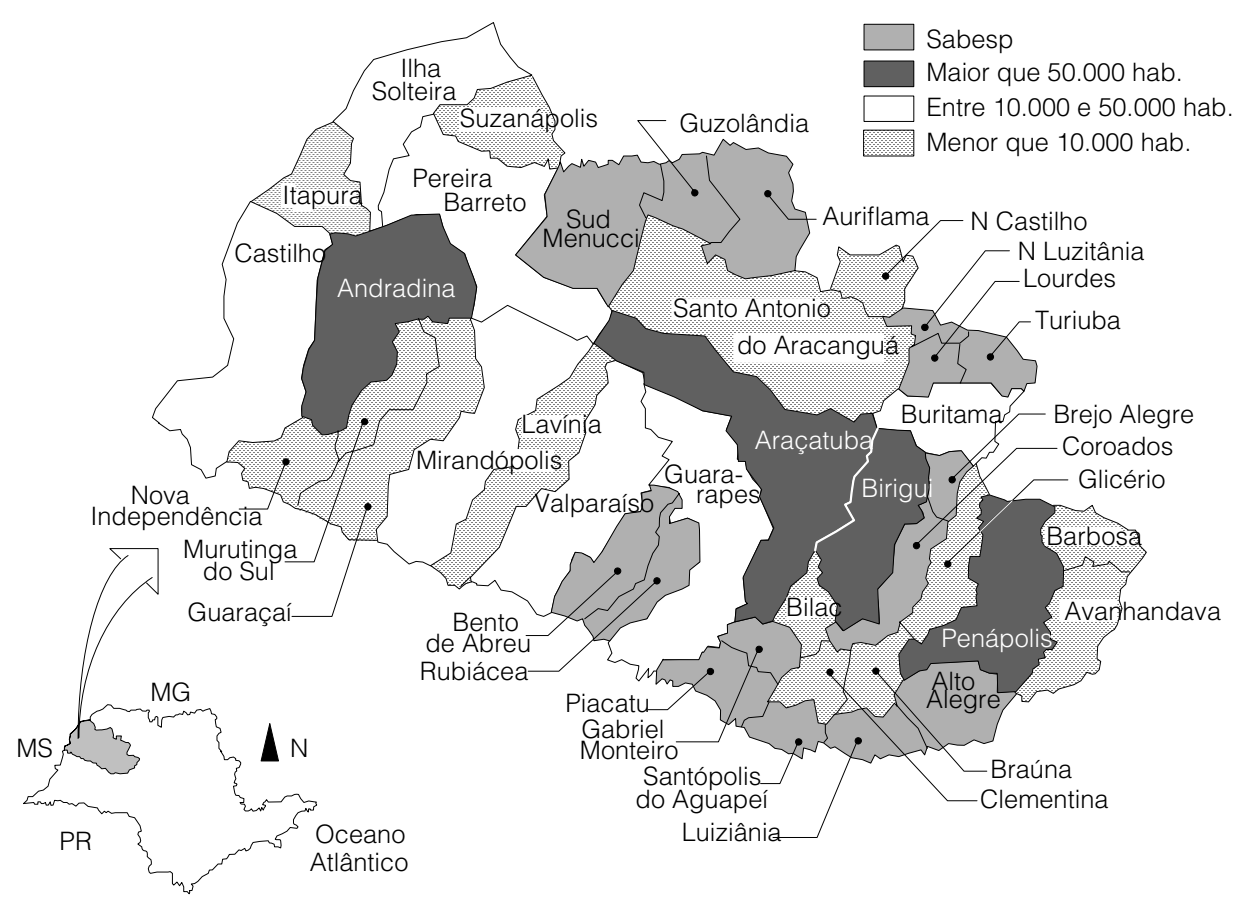

Figura 1 - Microrregião de Araçatuba e os municípios inseridos na pesquisa

Municipal (IDH-M), um indicador socioeconômico que pode estar relacionado às dificuldades e limitações dos sistemas de abastecimento (FUNDAÇÃO JOÃO PINHEIRO, 2006). O Índice de Desenvolvimento Humano (IDH) constitui um índice estabelecido pelo Programa das Nações Unidas para o Desenvolvimento (PNUD), contemplando as condições atingidas por uma sociedade no tocante à educação (conhecimento), padrão de vida e longevidade. O IDH-M traduz uma adequação do primeiro para viabilizar sua aplicabilidade em nível municipal.

Em todas as análises, elaboraram-se estatísticas descritivas básicas dos diversos agrupamentos sugeridos e testes de hipóteses para se verificar a homogeneidade dos agrupamentos adotados.

\section{Metodologia de coleta e determinação da concentração de flúor}

As análises foram realizadas no Laboratório I da Direção Regional de Saúde de Araçatuba. As amostras não são de controle de qualidade dos sistemas, e sim de fiscalização, cumprindo o Programa de Vigilância da Qualidade da Água da Secretaria Estadual da Saúde. As análises gozam de caráter oficial e têm fé pública.

O procedimento de coleta é padronizado pela Secretária Estadual da Saúde por meio do Centro de Vigilância Sanitária, além de ser padrão em todas as regionais do Estado. Coletaram-se as amostras em pontos aleatórios, buscando representar todo o sistema da rede de distribuição. Os pontos escolhidos foram sempre os do cavalete e, na ausência de torneira nesse, outro ponto abastecido diretamente pela rede.
As amostras foram coletadas em frascos reutilizáveis de polietileno de 500 ou $1.000 \mathrm{~mL}$ ou em sacos plásticos de 1.000 $\mathrm{mL}$ descartáveis, já que a mesma amostra serviu para a determinação de outros parâmetros físico-químicos, além de o maior volume de água coletada permitir a reavaliação da análise caso necessário.

As análises foram realizadas com o método potenciométrico com eletrodo íon-seletivo, adequado para concentrações de flúor de 0,1 até $10 \mathrm{mg} \cdot \mathrm{L}^{-1}$, a adição de tampão elimina interferências e, portanto, a necessidade de destilação prévia. Uma das vantagens desse método é a simplicidade e rapidez, além da alta seletividade. O equipamento usado foi um Analisador de íons, marca Mettler Toledo, com agitador magnético modelo 258 da Fanem.

Em análise de rotina, um desvio padrão de 1 mv é comum, sendo que os resultados analíticos frequentemente se encontram na faixa de erro de 5 a 10\%. Com cuidados especiais, esses erros podem ser reduzidos para a faixa de 1 a $2 \%$.

\section{Concentrações de flúor avaliadas}

Especificamente para Araçatuba, de acordo com a Secretaria de Agricultura e Abastecimento, a média das temperaturas máximas atingiu $30,1^{\circ} \mathrm{C}$ no período de 2000 a 2005, culminando na concentração recomendada de flúor de 0,70 mg..-1. Para o objetivo da pesquisa, definiu-se a concentração ideal de flúor inserida no intervalo 0,60 a 0,80 mg. $\mathrm{L}^{-1}$. A ausência de estações meteorológicas na 
quase totalidade dos demais municípios concorreu para definição da mesma concentração para toda microrregião.

Devido à constatação de que os aparelhos de leitura digital apresentam resoluções de até três casas decimais, o intervalo aceitável definido na pesquisa estendeu-se para 0,56 a 0,84 mg. $\mathrm{L}^{-1}$, aumentando assim o número de análises dentro do padrão.

\section{Verificação da homogeneidade dos agrupamentos adotados}

Considerou-se um total de 5.157 determinações laboratoriais de teor de flúor obtidas no período entre 2001 e 2005. Para verificar a homogeneidade dos agrupamentos adotados e, consequentemente, a pertinência da classificação adotada para os sistemas, empregou-se o teste de Kruskal Wallis (HELSEL; HIRCH, 2002). O teste aplica-se a dados ordinais, ou seja, dados passíveis de serem ordenados em uma sequência lógica, tal como baixo, médio e alto. Os dados são ordenados numa matriz $\mathrm{O}_{\mathrm{ij}}$ em que cada coluna corresponde a um grupo de dados e cada linha corresponde às observações agrupadas numa mesma categoria. Cada grupo de dados pode corresponder a repetições de um experimento, diferentes locais de amostragem ou, no caso deste trabalho, de diferentes mananciais e agrupamentos populacionais.

As categorias de resposta adotadas foram: não atende abaixo (NA-), atende (A) e não atende acima (NA+), correspondendo respectivamente a $\mathrm{F}<0,56 \mathrm{mg} \cdot \mathrm{L}^{-1}, 0,56 \leq \mathrm{F} \leq 0,84 \mathrm{mg} \cdot \mathrm{L}^{-1}$ e $\mathrm{F}>$ $0,84 \mathrm{mg} \cdot \mathrm{L}^{-1}$

O teste verifica se houve uma mudança na distribuição dos dados observados, sendo que a hipótese nula $\mathrm{H}_{0}$ é que a proporção de dados em cada categoria de resposta é a mesma para cada grupo. Uma vez encontrada diferença entre grupos, usualmente, interessa determinar qual grupo difere dos demais por meio de múltiplos testes de comparação, eliminando-se colunas até que se verifique $\mathrm{H}_{0}$.

\section{Resultados e discussão}

Em relação ao tipo de captação, dos 40 municípios envolvidos, oito se suprem, sendo quatro exclusivamente, de manancial superficial, sete captam, sendo dois exclusivamente no aquífero Guarani, e 28 se suprem exclusivamente de manancial subterrâneo. Tais distinções são contempladas na Figura 2.

A distribuição percentual das amostras nas três faixas adotadas na análise apresentou mais da metade $(51,6 \%)$ não atendendo ao padrão de fluoretação $\left(0,56-0,84 \mathrm{mg} \cdot \mathrm{L}^{-1}\right), 41 \%$ abaixo e $11 \%$ acima desse intervalo. Os dados amostrais distribuem-se por 40 municípios dos mais variados tamanhos populacionais, capacidade de investimentos, capacitação técnica e tipos de mananciais explorados. Esses percentuais serão detalhados visando delinear as características comuns que possam explicar a eficiência da fluoretação, abrangendo os aspectos que contribuem tanto negativamente quanto positivamente. A análise será efetuada, inicialmente, sob três aspectos: o tipo de manancial, a estrutura (o tipo de administração e porte do sistema de abastecimento) e o conjunto dos dados.

\section{Tipo de manancial}

Quanto ao tipo de manancial, em primeira análise, agruparamse os oito municípios que se suprem total ou parcialmente de águas superficiais, doravante denominados agrupamento superficial, comparando-os aos 32 que utilizam exclusivamente água subterrânea, doravante denominado agrupamento subterrâneo. Na Figura 3 apresentam-se tais resultados.

Considerando-se a importância e as características diferenciadas do aquífero Guarani, o tipo de manancial foi estudado ainda sob outro enfoque. Os municípios que se suprem total ou parcialmente desse aquífero foram reunidos no agrupamento doravante denominado profundo, comparando seu desempenho com os 33 restantes, doravante denominados demais. Na Figura 4 ilustra-se essa situação.

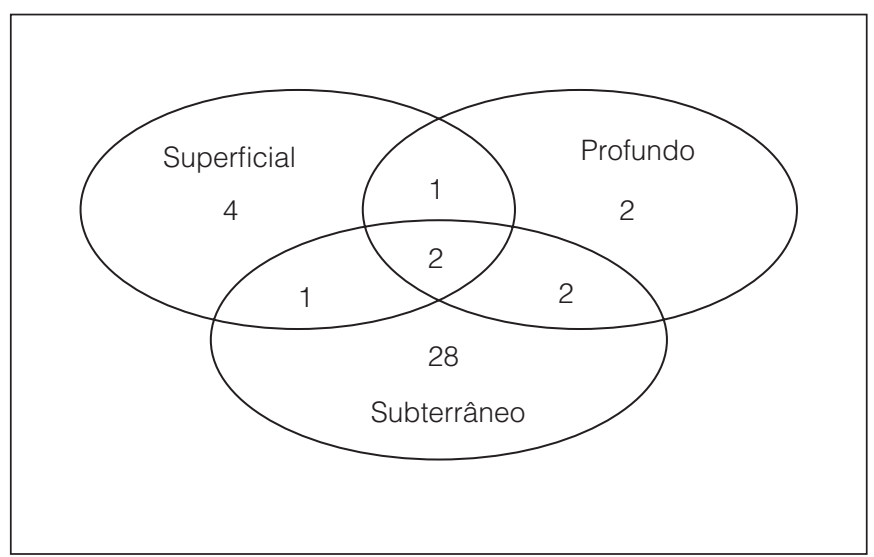

Figura 2 - Número de municípios amostrados e seus respectivos tipos de mananciais

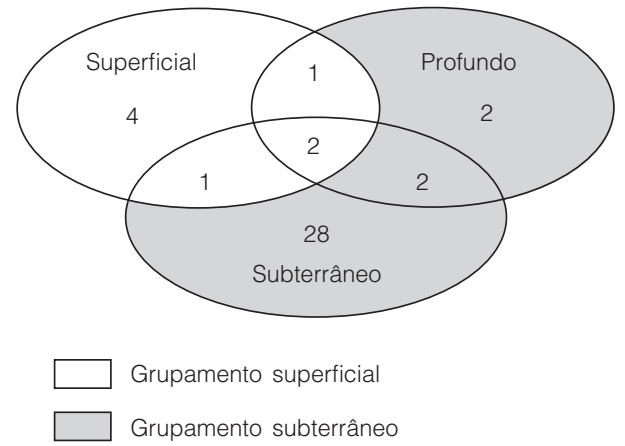

Figura 3 - Representação esquemática dos agrupamentos superficial e subterrâneo integrantes do universo amostral 
Na Tabela 2 apresentam-se os resultados obtidos por faixa de teor de flúor considerando os agrupamentos superficial e subterrâneo.

Os resultados da Tabela 2 apontam supremacia dos sistemas que exploram mananciais de superfície. A razão para tal superioridade, sem dúvida, se deve ao fato de que captação de água superficial requer, obrigatoriamente, instalações físicas de tratamento, recursos humanos e laboratoriais, geralmente não presentes em sistemas que exploram o subsolo.

Em uma segunda análise, a Tabela 3 mostra os resultados obtidos por faixa de teor de flúor considerando os agrupamentos profundo e demais

Vale destacar, na Tabela 3, a grande diferença na faixa acima de $0,84 \mathrm{mg} \cdot \mathrm{L}^{-1}$, sendo que o maior valor pelos mananciais profundos se explica pela ocorrência natural desse íon na água natural. O agrupamento profundo apresenta aproximadamente $60 \%$ de amostras a mais que o agrupamento demais no intervalo acima do preconizado. Isso se deve ao fato de as formações geológicas Botucatu e Piramboia, nas quais se inserem as mencionadas captações subterrâneas, apresentarem flúor nas águas naturais. Nenhum sistema de abastecimento promove a remoção do fluoreto, apenas a diluição em alguns casos.

\section{Estrutura}

A análise quanto ao tipo de administração combinado ao porte do sistema deve considerar inicialmente o grupo dos sistemas

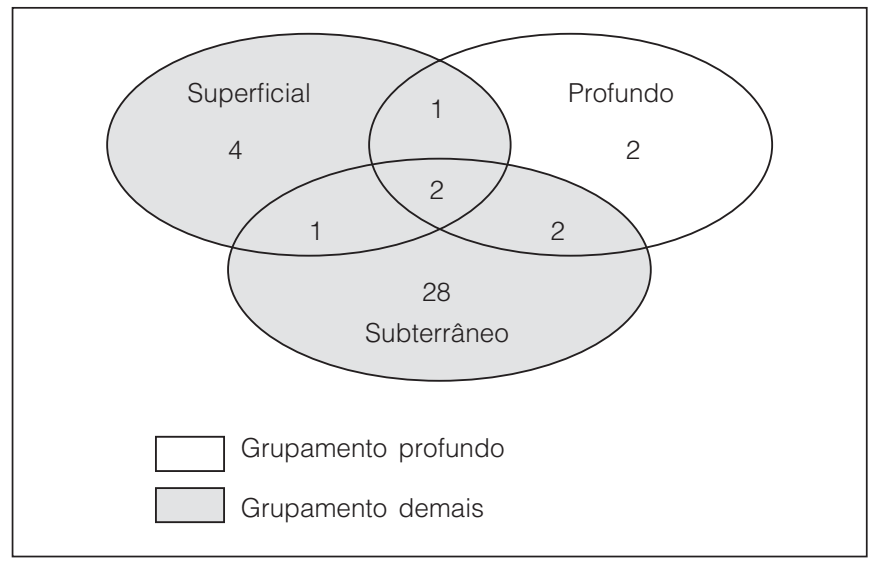

Figura 4 - Representação esquemática dos agrupamentos profundo e demais.

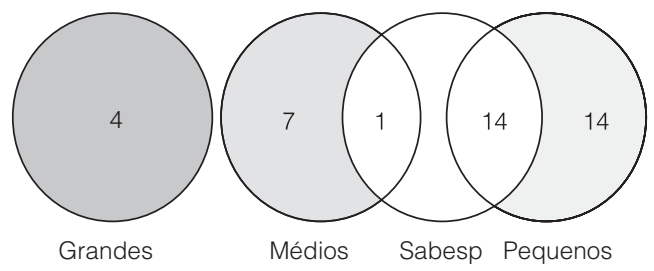

Figura 5 - Representação esquemática dos agrupamentos de estrutura. sob concessão da Sabesp, independentemente de outras características, tendo em vista o padrão mais uniforme de operação da companhia. O outro grupo seria naturalmente o dos sistemas sob administração das prefeituras municipais. Entretanto, esse grupo será subdividido tendo em vista as diferenças no porte dos sistemas envolvidos. Conforme mencionado em Metodologia, a população dos municípios constituiu um critério utilizado para avaliar o porte do sistema. Dessa forma, o desdobramento com relação à estrutura contará com os seguintes agrupamentos populacionais: grandes $(G)$, municípios com mais de 50 mil habitantes; médios (M), cujas populações estão entre 10 mil e 50 mil habitantes, e pequenos (P), com população inferior a 10 mil habitantes. Na Figura 5, sintetiza-se essa caracterização do universo amostral.

A estatística descritiva para os distintos agrupamentos populacionais está apresentada na Tabela 4.

Os resultados da Tabela 4 parecem indicar, além da maior eficiência do agrupamento Sabesp, que o porte do sistema relaciona-se à concentração de flúor devido à similaridade dos percentuais de atendimento ao padrão entre os municípios grandes e médios. A explicação foca-se na necessidade dos maiores sistemas de instalações mais complexas e, consequentemente, equipe de operação mais qualificada. Vale também mencionar a relevância do padrão operacional da Sabesp, que se manifesta no maior percentual de

Tabela 2 - Distribuição das amostras em relação ao padrão de atendimento nos agrupamentos superficial e subterrâneo

\begin{tabular}{|c|c|c|c|c|c|c|c|}
\hline \multirow{2}{*}{ Agrupamento } & \multicolumn{2}{|c|}{ Abaixo } & \multicolumn{2}{|c|}{ Atende } & \multicolumn{2}{|c|}{ Acima } & \multirow{2}{*}{ Total } \\
\hline & Número & $\%$ & Número & $\%$ & Número & $\%$ & \\
\hline Superficial & 496 & 29,6 & 1.003 & 60,0 & 173 & 10,4 & 1.672 \\
\hline Subterrâneo & 1.596 & 45,8 & 1.494 & 42,9 & 395 & 11,3 & 3.485 \\
\hline Região (total) & 2.092 & 40,6 & 2.497 & 48,4 & 568 & 11,0 & 5.157 \\
\hline
\end{tabular}

Tabela 3 - Distribuição das amostras em relação ao padrão de atendimento nos agrupamentos profundo e demais

\begin{tabular}{|c|c|c|c|c|c|c|c|}
\hline \multirow{2}{*}{ Agrupamento } & \multicolumn{2}{|c|}{ Abaixo } & \multicolumn{2}{|c|}{ Atende } & \multicolumn{2}{|c|}{ Acima } & \multirow{2}{*}{ Total } \\
\hline & Número & $\%$ & Número & $\%$ & Número & $\%$ & \\
\hline Profundo & 537 & 32,7 & 857 & 52,3 & 246 & 15,0 & 1.640 \\
\hline Demais & 1.555 & 44,2 & 1.640 & 46,6 & 322 & 9,2 & 3.517 \\
\hline Região (total) & 2.092 & 40,6 & 2.497 & 48,4 & 568 & 11,0 & 5.157 \\
\hline
\end{tabular}

Nota: Abaixo $\rightarrow \mathrm{F}<0,56 \mathrm{mg} \cdot \mathrm{L}^{-1} ;$ Atende $\rightarrow 0,56 \leq \mathrm{F} \leq 0,84 \mathrm{mg} \cdot \mathrm{L}^{-1} ;$ Acima $\rightarrow \mathrm{F}>0,84 \mathrm{mg} \cdot \mathrm{L}^{-1}$

Tabela 4 - Distribuição das amostras em relação ao padrão de atendimento nos agrupamentos de estrutura

\begin{tabular}{lrrrrrrr}
\multirow{2}{*}{ Agrupamento } & \multicolumn{2}{c}{ Abaixo } & \multicolumn{2}{c}{ Atende } & \multicolumn{2}{c}{ Acima } & \multirow{2}{*}{ Total } \\
\cline { 2 - 7 } & Número & $\%$ & Número & $\%$ & Número & $\%$ & \\
Sabesp & 303 & 27,1 & 770 & 68,8 & 46 & 4,1 & 1.119 \\
Grandes & 514 & 35,4 & 757 & 52,1 & 183 & 12,5 & 1.454 \\
\hline Médios & 359 & 33,6 & 549 & 51,4 & 160 & 15,0 & 1.068 \\
Pequenos & 916 & 60,4 & 421 & 27,8 & 179 & 11,8 & 1.516 \\
\hline Total & 2.092 & 40,6 & 2.497 & 48,4 & 568 & 11,0 & 5.157 \\
\hline
\end{tabular}

Nota: Abaixo $\rightarrow \mathrm{F}<0,6 \mathrm{mg} \cdot \mathrm{L}^{-1}$; Atende $\rightarrow 0,6 \leq \mathrm{F} \leq 0,8$; Acima $\rightarrow \mathrm{F}>0,8 \mathrm{mg} \cdot \mathrm{L}^{-1}$ 
atendimento ao padrão para um conjunto de 14 sistemas de pequeno porte, como mostra a Figura 6.

Uma análise singela, relacionando o percentual de análises dentro do padrão e o número total de amostras, indica a mesma tendência. Sistemas de maior porte, com maior frequência de monitoramento da qualidade da água de consumo, podem apresentar melhor padrão operacional. Essa tendência confirma-se pela Figura 6, na qual o gráfico (B) foi elaborado excluindo-se os sistemas operados pela Sabesp.

Vale salientar que o próprio aumento do coeficiente de determinação $\left(R^{2}\right)$ após a exclusão dos sistemas operados pela Sabesp tende a ratificar a assertiva anterior

\section{Conjunto dos dados amostrais}

A Tabela 5 apresenta a média, a mediana e o desvio padrão de todas as 5.157 análises efetuadas dentro dos oito agrupamentos estabelecidos em Metodologia.

A partir da Tabela 5, percebe-se:

I) a supremacia do agrupamento superficial, que conta com apenas oito municípios sendo quatro exclusivamente abastecidos por água superficial, sobre o subterrâneo tanto no quesito média como no desvio padrão;
II) idem para o agrupamento profundo, que conta com apenas sete municípios, sendo dois exclusivamente abastecidos pelo aquífero Guarani, sobre os demais.

III) em relação ao porte e administração dos sistemas, verifica-se uma notável coincidência da média entre os agrupamentos Sabesp, grandes e médios, com o progressivo crescimento do desvio padrão.

Na Figura 7 apresentam-se os valores máximo e mínimo e os quartis dos agrupamentos superficial e subterrâneo, e profundo e demais.

Tabela 5 - Estatística descritiva das concentrações de flúor dos oito agrupamentos

\begin{tabular}{lccc} 
Agrupamento & Mediana & Média & Desvio padrão \\
\hline Superficial & 0,60 & 0,63 & 0,22 \\
Subterrâneo & 0,60 & 0,54 & 0,35 \\
Profundo & 0,60 & 0,64 & 0,26 \\
\hline Demais & 0,60 & 0,54 & 0,33 \\
\hline Sabesp & 0,60 & 0,62 & 0,16 \\
\hline Grandes & 0,60 & 0,62 & 0,25 \\
\hline Médios & 0,60 & 0,62 & 0,34 \\
Pequenos & 0,40 & 0,45 & 0,39 \\
\hline Total & 0,60 & 0,57 & 0,31 \\
\hline
\end{tabular}

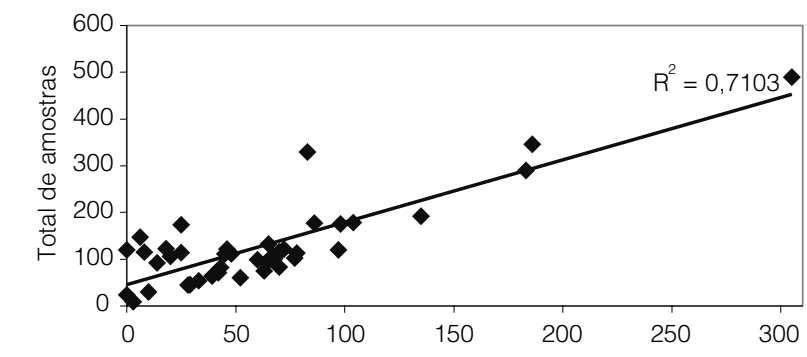

A

Amostras dentro do padrão

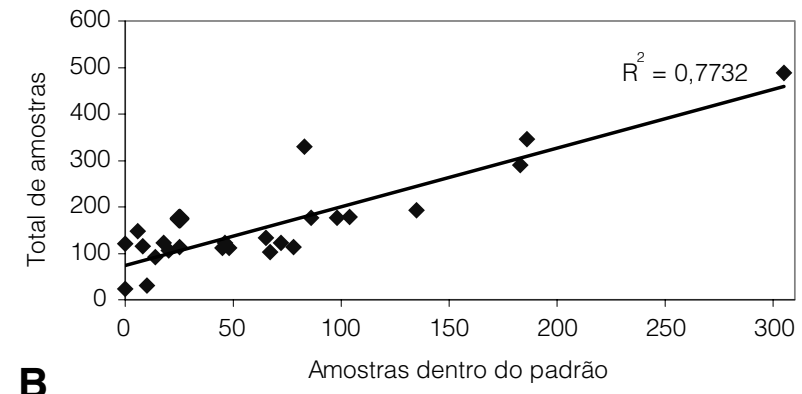

B

Figura 6 - Relação entre o número de amostras dentro do padrão e total de amostras, com (A) e sem (B) os sistemas operados pela Sabesp

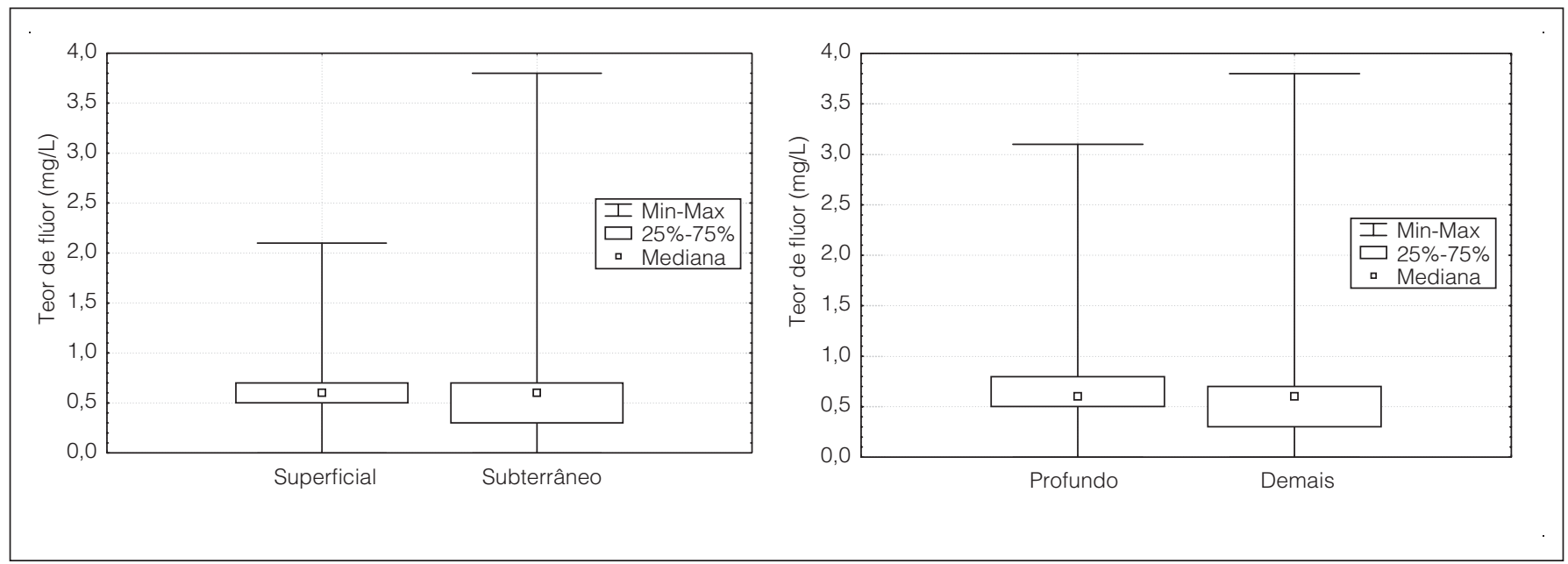

Figura 7 - Boxplot da concentração de flúor das amostras dos agrupamentos superficial, subterrâneo, profundo e demais 
A análise da Figura 8 corrobora a assertiva anterior, apontando maior uniformidade nas concentrações de flúor nos sistemas que utilizam mananciais superficiais. A justificativa fundamenta-se no fato de os oito sistemas de abastecimento que compõem esse agrupamento representarem $62 \%$ da população total da microrregião - cinco entre os sete maiores sistemas do universo amostral.

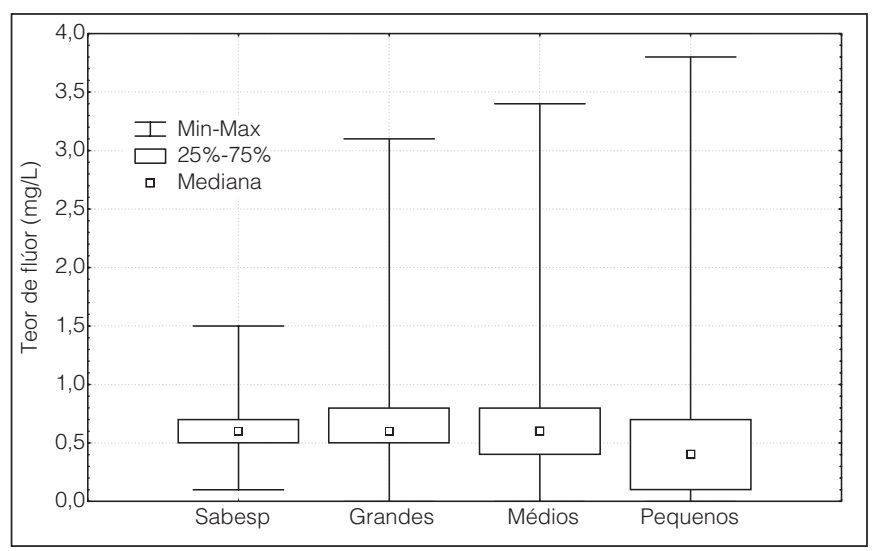

Figura 8 - Boxplot da concentração de flúor de todas as amostras dos quatro agrupamentos de estrutura

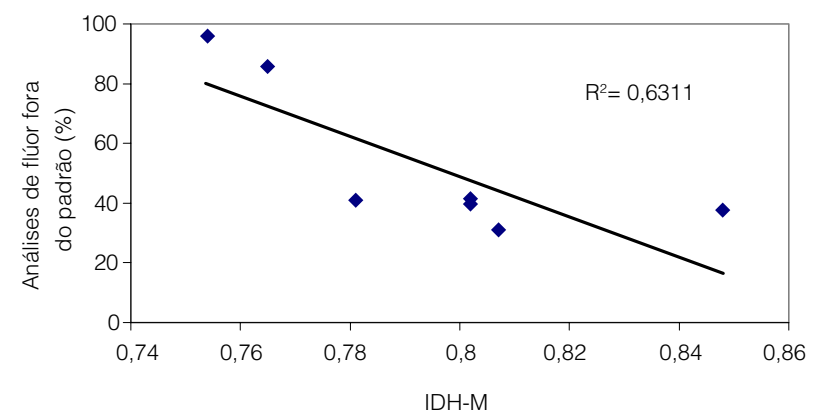

Figura 9 - Associação entre o IDH-M e o percentual de amostras fora do intervalo para concentração de flúor
No mesmo contexto, na Figura 8 apresentam-se os valores máximo e mínimo e os quartis do total de amostras dos quatro agrupamentos de estrutura.

A análise da Figura 8 aponta idêntica constatação quanto à maior uniformidade nas concentrações de flúor para os 15 sistemas operados pela Sabesp. A comparação do desempenho desses sistemas aos de mesmo porte - 14 dos quais foram classificados como pequenos, conforme a Figura 5 -, novamente confirma a eficácia da padronização operacional da Sabesp.

Em uma avaliação distinta, as limitações de operação dos sistemas de abastecimento parecem guardar relação com outros indicadores socioeconômicos, tais como o IDH-M. A despeito da pequena amostra - para apenas sete municípios dessa microrregião determinou-se o IDH-M (FUNDAÇÃO JOÃO PINHEIRO, 2006) -, a Figura 9 indica tendência dos menores valores desse parâmetro a se associarem aos sistemas de abastecimento com percentuais mais baixos de atendimento ao intervalo recomendado para concentração de flúor. Vale ressaltar que esse extrato corresponde a 25\% do universo amostral da pesquisa.

\section{Aplicação do teste Kruskal-Wallis}

Nas Tabelas 5 e 6 apresentam-se os resultados dos testes KruskalWallis (KW) para os agrupamentos definidos, nos quais comparamse o valor calculado (K) ao valor esperado pela distribuição $\chi^{2}$ com k-1 grau de liberdade (Klim).

Face à mencionada eficiência maior dos sistemas operados pela Sabesp, efetuou-se análise quanto ao tipo de manancial explorado excluindo-se aqueles que se suprem de águas de superfície e aqueles administrados por essa companhia estadual. Esse agrupamento foi dividido em profundo e não profundo. Na Figura 10 ilustra-se a distribuição dos municípios segundo o novo rearranjo.

Na Tabela 7 apresentam-se o número de análises e os percentuais de amostras referentes aos novos agrupamentos.

Tabela 5 - Resumo do teste KW para faixa de concentrações de flúor que estão abaixo atendem, e acima nos 40 municípios analisados

\begin{tabular}{lrrrcc} 
Teste entre & \multicolumn{1}{c}{ K } & Klim & Rejeita & Atendimento (\%) & Conclusão \\
Superficiais versus subterrâneos & 78,49 & 5,99 & Sim & $60,0 \times 42,9$ & SUP $>$ SUB \\
Profundos versus demais & 76,72 & 5,99 & Sim & $52,3 \times 46,6$ & PROF $>$ DEM \\
Sabesp versus grandes versus médios versus pequenos & 235,06 & 12,59 & Sim & $68,8 \times 52,1 \times 51,4 \times 27,8$ & Diferentes \\
Sabesp versus grandes versus médios & 2,41 & 9,49 & Não & $68,8 \times 52,1 \times 51,4$ & Iguais, logo S $=$ G = M > P
\end{tabular}

Tabela 6 - Resumo do teste KW para faixa de concentrações de flúor de não atendimento ou atendimento nos 40 municípios analisados

\begin{tabular}{lrrrcc} 
Teste entre & \multicolumn{1}{c}{ K } & Klim & Rejeita & Atendimento (\%) \\
Superficiais versus subterrâneos & 132,55 & 3,84 & Sim & $60,0 \times 42,9$ \\
Profundos versus demais & 14,17 & 3,84 & Sim & $52,3 \times 46,6$ \\
\hline Sabesp versus grandes versus médios versus pequenos & 456,88 & 7,81 & Sim & $68,8 \times 52,1 \times 51,4 \times 27,8$ \\
\hline Sabesp versus grandes versus médios & 91,78 & 5,99 & Sim & $68,8 \times 52,1 \times 51,4$ & PROF > DEM \\
Grandes versus médios & 0,11 & 5,02 & Não & Diferentes \\
Médios versus pequenos & 149,21 & 5,02 & Sim & $51,4 \times 27,8 \quad$ Diferentes \\
\hline
\end{tabular}


Como seria de esperar, observa-se a supremacia do agrupamento profundo sobre o não profundo no que diz respeito ao atendimento ao padrão. Essa assertiva foi confirmada pelo teste KW que revelou $\mathrm{K}=72,25$, para $\operatorname{Klim}(2 ; 95)=5,99$ (para 2 graus de liberdade e 95\% de nível de significância), portanto rejeitando a hipótese $\mathrm{H}_{0}$ da igualdade na proporção dos dados de cada agrupamento. A confirmação da expectativa centra-se no maior porte dos municípios abastecidos por poços profundos - desse extrato da amostra, a totalidade dos maiores sistemas utiliza esse tipo de manancial subterrâneo - associado à melhor acuidade na operação. Como normalmente os poços do aquífero Guarani apresentam maiores vazões, o sistema também adquire controle mais simples, em oposição às redes com vários poços freáticos normalmente presentes em caso de manancial subterrâneo nos aquíferos Serra Geral e Bauru. Portanto, a divisão dos municípios abastecidos por água subterrânea segundo o aquífero explorado reflete também a estrutura do sistema, incluindo padrões de gerenciamento e capacitação dos recursos humanos

\section{Conclusões}

A partir dos resultados das 5.157 análises de flúor realizadas no período de 2001 a 2005, algumas conclusões podem ser alinhavadas:

- mais da metade das amostras (51,6\%) não atendeu ao padrão de fluoretação no que tange à concentração de flúor de 0,56 a $0,84 \mathrm{mg} \cdot \mathrm{L}^{-1}$;

- a administração dos sistemas de abastecimento de água de grande e médio porte pelas prefeituras municipais tende a equalizar o percentual de atendimento ao padrão de fluoretação (52 e $47 \%$, respectivamente), ainda que em nível inferior aos sistemas operados pela Sabesp (69\%);

- como em outros países, as maiores limitações do atendimento ao padrão de fluoretação - e à própria manutenção da qualidade de água - verificaram-se mais claramente nos sistemas de pequeno porte operados pelas prefeituras municipais (28\%). Todavia, tais limitações não se manifestaram nos sistemas operados pela Sabesp, enfatizando a relevância da operação no atendimento à norma;

- há nítida tendência de os sistemas de maior porte e com IDH-M mais elevado apresentarem maior percentual de atendimento ao padrão de fluoretação;

- quanto ao tipo de manancial, os testes estatísticos revelaram diferença significativa entre o desempenho no atendimento ao padrão legal de flúor do agrupamento superficial (60,0\%)
Tabela 7 - Distribuição das amostras em relação ao padrão de atendimento nos agrupamentos profundo e não profundo

\begin{tabular}{lrrrrrrrr} 
& \multicolumn{3}{c}{ Abaixo } & \multicolumn{2}{c}{ Atende } & \multicolumn{2}{c}{ Acima } & \multirow{2}{*}{ Total } \\
\cline { 2 - 7 } & Número & $\%$ & Número & $\%$ & Número & $\%$ & \\
Profundo & 233 & 37,2 & 259 & 41,9 & 126 & 20,4 & 618 \\
Demais & 1.087 & 56,9 & 594 & 31,1 & 229 & 12,0 & 1.910 \\
\hline Total & 1.320 & 52,2 & 853 & 33,7 & 355 & 14,1 & 2.528 \\
\hline
\end{tabular}

Nota: Abaixo $\rightarrow \mathrm{F}<0,6 \mathrm{mg} \cdot \mathrm{L}^{-1} ;$ Atende $\rightarrow 0,6 \leq \mathrm{F} \leq 0,8$; Acima $\rightarrow \mathrm{F}>0,8 \mathrm{mg}^{\mathrm{L} \mathrm{L}^{-1}}$

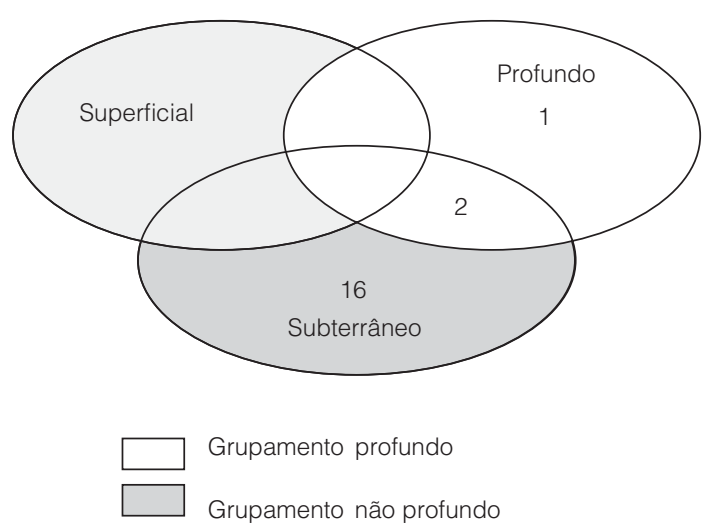

Figura 10 - Número de municípios segundo os agrupamentos profundo e não profundo

e o subterrâneo $(42,9 \%)$. Dentre os municípios que se suprem de águas subterrâneas, o grupo que explora o aquífero Guarani teve desempenho superior $(41,9 \%)$ aos outros $(31,1 \%)$;

- $\quad$ por fim, os resultados deste estudo evidenciam a relevância do papel da vigilância sanitária na garantia da qualidade da água de consumo, principalmente para os sistemas de pequeno porte operados por prefeitura municipais que, mesmo no Estado mais abastado da Federação, comumente carecem de pessoal qualificado para sua operação.

\section{Agradecimentos}

Os autores agradecem aos revisores do artigo pelas sugestões, aos técnicos do Laboratório I da Direção Regional de Saúde de Araçatuba, especialmente à Farmacêutica-Bioquímica e Mestre em Análises Clínicas, Aparecida de Fátima Michelin, e à Química Tereza Marilene Bronharo pela elaboração dos laudos utilizados neste trabalho, à Diretora Técnica da Vigilância Sanitária enfermeira Michie Omomo Barão pelo incentivo à realização do trabalho, e à Fundação de Amparo à Pesquisa do Estado de Minas Gerais (Fapemig) pelo apoio ao terceiro autor no contexto do Programa Pesquisador Mineiro (Processo 4754-6). 


\section{Referências}

BRASIL. Ministério da Saúde. Portaria 518. Normas e padrão de potabilidade da água destinada ao consumo humano. Brasília, DF, março de 2004.

Ministério da Saúde. Portaria 56/BSB. Normas e padrão de potabilidade no Brasil. Brasília, mar. 1977.

FUNDAÇÃO JOÃO PINHEIRO. Atlas de desenvolvimento humano no Brasil. Rio de Janeiro: PNUD/IPEA/Fundação João Pinheiro, 2006.

HELSEL, D.R.; HIRSCH, R.M. Statistical methods in water resources. Techniques of water resources investigations of the United States geological survey. Book 4, Hydrologic Analysis and Interpretation, 2002. [On-line]. Disponível em http://water.usgs.gov/pubs/twri/twri4a3. Acesso em: 7 abr. 2009.

LALUMANDIER, J.A.; JONES, J.L. Fluoride concentrations in drinking water, Journal of the American Water Works Association, v. 91, n. 10, p. 42-51, Oct. 1999.

LIMA, F.G. et al Vinte e quatro meses de heterocontrole da fluoretação das águas de abastecimento público de Pelotas (RS). Cadernos de Saúde Pública, v. 20, n. 2, p.422-429, 2004.

MAIA, L.C. et al Controle operacional da fluoretação da água de Niterói, Rio de Janeiro, Brasil. Cadernos de Saúde Pública, v. 19, n. 1, p. 61-67, 2003.

RAMIRES, I. et al External control over the fluoridation of the public water supply in Bauru, São Paulo, Brazil. Revista de Saúde Pública, v. 40, n. 5, p. 883-889, Oct. 2006.

REEVES, T.G. Water fluoridation. In: LETTERMAN, R.D. Water quality and treatment. $5^{\text {th }}$ Ed. USA: McGraw-Hill, p.15.1-15.19, 1999. 